\title{
E-podium Technology: A medium of managing Knowledge at Al Buraimi University College via M- learning
}

\author{
Mostafa Al Emran \\ The British University in Dubai \\ Dubai, UAE \\ 120128@student.buid.ac.ae
}

\author{
Khaled Shaalan \\ The British University in Dubai \\ Dubai, UAE \\ Khaled.shaalan@buid.ac.ae
}

\begin{abstract}
Al Buraimi University College (BUC) is one of the well-known private colleges in The Sultanate of Oman, in Al Dhahra region, which is affiliated with California State University Northridge (CSUN), USA. It is well-known that Knowledge management can help in identifying the gaps and weaknesses in organizations and suggesting effective solutions. This paper focuses on the learning process itself. A lack in knowledge management has been identified where BUC follows a traditional way of delivering the teaching-material to students where there is no means of educational management system that is capable of handling or storing the entire lecture's material. BUC's students, specifically who do not regularly attend lectures due to their work obligations, are having problems with getting access to the course material. This study sheds the light on how Epodium technology along with the recent Mobile technology can solve this kind of problems. The proposed solution is novel which combines four different technological resources: M-learning, Epodium, BUC Website and Video Conferencing. E-podium device allows recording of lectures on real time. Mobile learning allows the lecturers to upload/update the course-material to their personal web page at their convenience. Students at the same time will get an access to lectures' material as well as to the course-material. Our study showed the proposed Knowledge Management model in BUC helps in getting the most out of knowledge resources that facilitate the generation and access to the teaching material.
\end{abstract}

Keywords-M-learning, E-podium, Knowledge Management, Course-material, Video-Conferencing.

\section{INTRODUCTION AND BACKGROUND}

Al Buraimi University College (BUC) is one of the well-known universities in The Sultanate of Oman which supports innovative technologies. The study at BUC started on the $2^{\text {nd }}$ semester of the year (2003-2004). In order to achieve an extreme benefit, acquiring experiences and to come up with advanced academic expertise, BUC is affiliated with California State University Northridge (CSUN), USA. BUC struggles to be a strategic partner and contributor by providing multiple services in the field of higher education, scientific research and community service [AI-Buraimi University College, 2010]. BUC seeks to provide various educational opportunities through various academic fields in order to meet the market demands/requirements.

\subsection{Knowledge Management at BUC \& Related Work}

This study focuses on how the learning process is managed in such a way it gets the most out of knowledge resources that facilitate the generation and access to the teaching material. BUC follows the traditional way of teaching where the lecturer regularly puts the lecture-material in the concerned class's computer and starts illustrating the lecture without relying on an educational knowledge sharing system. Absent/remote students are facing a difficulty in acquiring the delivered lecture in the class. This study sheds the light on how students and specifically those who are not able to attend the class regularly due, for example, to their work obligations.

E-podium technology has been successfully implemented in King Saud University, Kingdom of Saudi Arabia, in order to facilitate keeping track of the lecture-material during the course of teaching. Students can easily access the recorded lecture via accessing The Learning Management System (LMS) through E-learning technology, e.g. by means of their laptops, or M-learning technology, e.g. by means of mobile devices. A survey was conducted within the university to assess the students' attitudes and perceptions towards Epodium. Survey results revealed that $80-90 \%$ of the 
students were significantly positive towards Epodium [Abachi \& Muhammad 2013].

Mobile learning technology has been implemented in several leading institutions around the world such as Canada College [Enriquez 2010], Abilene Christian University, USA [Perkins \& Saltsman 2010] and proved a significant positive trend in the education field. M-learning has facilitated videoconferencing among the students and with their lecturers [Erkollar \& Oberer 2012]. M-learning could bring many opportunities in the education field and specifically through managing the learning process via their capability to accomplish the tasks properly. In this study, we focus on how M-learning in cooperation with E-podium technology can be used to manage the course-material delivered within the class and make them available for students even though when they are not attending the class.

\section{BACKGROUND}

\subsection{E-podium}

E-podium is an electronic device that can be used to record the lecture while the lecturer delivers his/her lecture in the class [Abachi \& Muhammad 2013]. The recorded lecture then will be uploaded to The Learning Management Service (LMS). Epodium controls the classroom's components by a special Hardware and Software packages [King Saud University, 2009]. It is designed to facilitate and make it easy to spread the knowledge to a large number of audiences. This device has proved itself as one of the efficient mediums for sharing knowledge in large organizations as well as spreading new ideas that bring many people together [ePODIUM, 2008]. The impact of using such technology in the education field can positively affect the face-to-face sessions and switch it to online learning sessions [Yang et al., 2010].

\subsection{Mobile Learning}

Mobile learning simply can be defined as the learning that is based on mobile devices (e.g. smartphones, tablets). Different researchers have provided different definitions for mobile learning such as learning that is both formal and informal [Gikas \& Grant 2013] and knowledge acquisition through the use of mobile technology [Geddes 2004]. Mobile learning has been considered as a mechanism that enhances student's learning experience [Liu et al., 2010]. Moreover, mobile technologies make it easy for accessing multimedia material, e.g. audio and video materials, through their tools and services [Abachi \& Muhammad 2013]. Collectively, M-learning can bring distance learners to learn and collaborate together, enhance students' communication among each other and with their educators, a quick and efficient technology for accessing material anytime, anywhere.

\section{PROBLEM IDENTIFICATION}

This paper attempts to identify the major issues encountered in the learning process by one of the fast growing Omani universities. Solutions are proposed from the knowledge management perspective that requires the cooperation of the $\mathrm{M}$ learning with E-podium technology. Our study indicates the following major issues that are encountered by the students at BUC:

- Weakness in material management: The delivery of the material is through the concerned class's computer which is made available at the start of the lecture. The handing over is inefficient such that each student collects the material after the lecture is via their USB flash. The knowledge explained during the lecture is not documented in an electronic form and has to be observed and noted by the student himself. This valuable knowledge is subject to loss, either deliberately or by mistake, and depends on skills of each student. These complementary materials are essential for students who could not attend the class. This raises the need for learning management system in order to manage and keep track of all the course-lectures together.

- Material \& Assignments unavailability: many students are part time students. It is common practice that a student cannot attend classes, off course within the allowed attendance percentage, usually due to their work demands and obligations, e.g. students working at police departments, security sectors, emergency departments, and others, who the nature of their jobs make them either on call or work on shifts. The important question is, "how such students could get the lecture-material?" and even if they acquire it, how can they understand it? It is incontinent and impractical to ask the lecturer to repeat his lecture or parts from it. This is not only concerned with lecturematerial but also with assignment description provided in the class. We do not want any student who cannot attend the class to miss any point of assessment. The performance of students missing their lectures as well as their assignments is affected; sometimes this could lead to a failure and causes the student to repeat the course/module. This raises the need for tools that could be utilized to access the lecture, materials, and assessments.

- Lack in website management: BUC has a well-programmed website but it has limited usage. BUC website used only for announcements, pictures gallery and other information about the college. Few semesters only have been used to provide the 
courses'/modules' results. The website has not been used efficiently to support the learning process as well as to manage the coursematerial in order to be provided for the students. This raises the need for web content that supports the learning process.

\section{PROPOSED SOLUTION}

Knowledge Management has been effectively used in many organizations. It helps to identify the weaknesses and gaps in the education field within BUC. This study uses the potential effectiveness of Knowledge Management to determine and propose a solution that can solve/handle the identified problems. In comparison with similar research such as [Abachi \& Muhammad 2013], our proposed solution is novel, which combines four technologies altogether: M-learning, E-podium, University Website and Video Conferencing.

The proposed solution is shown in Fig. 1. The Epodium device is used to record the lecture while the lecturer delivers it in the class. The recorded lecture will be immediately uploaded to the lecturer's web page once the lecture is finished. Each lecturer should create a particular folder for the particular course that $\mathrm{s} /$ he is teaching in her/his scholar web page. Organizing the folders in this way can easily help the lecturer to upload the recorded lecture to the concerned course folder.

Once the recorded lecture is uploaded to the lecturer's web page, it can easily be accessed by the students at their convenient time using their mobile devices (e.g. tablets, smartphones). This part of the solution helps properly in improving the knowledge management of lectures' content within BUC in an effective way which enables documenting the knowledge sources (recordedlecture, presentations, and assessments) in an online electronic form (i.e. Lecturer's web page). This acquired knowledge can be easily transferred and exchanged through the students. Furthermore, students who are not able to attend the lecture can easily use their mobile devices and communicate with their lecturer via video-conferencing during the lecturer's office-hour to discuss issues regarding the material or the assignments via using any of the freely available chatting applications such as: Hangout, Skype, Mypeople, and many others. This part of the solution enables socialization where the students can interactively learn from their lecturers (i.e. tacit to tacit communication).

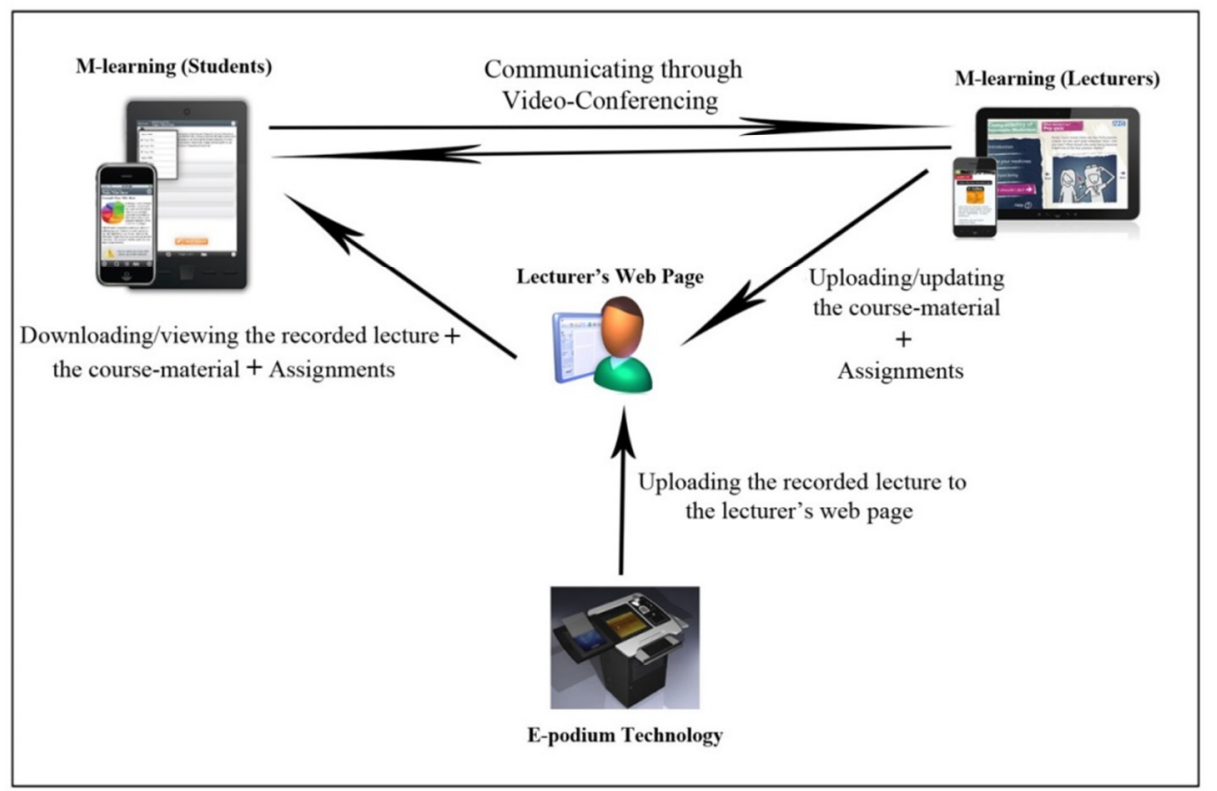

Fig. 1. Course-Material Management via combining (M-learning, E-podium, BUC Website and Video Conferencing) altogether.

To sum up, the proposed solution is aimed at achieving the following as compared with the current learning environment (i.e. the potential impacts on BUC organizational processes):

- Efficiency: quickly accessing and collecting the course-material as soon as it is uploaded to the lecturer's web page.

- Effectiveness: enhancing students' satisfaction regarding the material collection which is an emergent problem usually faced in BUC.

\section{RECOMMENDATIONS}

One of the main factors that should be taken into consideration when planning or deciding to apply any technology in any organization is the cost. The proposed solution is cost-effective where the only needed component is the E-podium device. All other technologies are already available. Mobile 
devices already exist and available by almost all of the students and lecturers. BUC website already exists as well; the proposed solution has leveraged its usage instead of being used for limited benefit.

The proposed solution enables both knowledge creation and transformation in which explicit knowledge has been created through using the $\mathrm{E}-$ podium technology which in turn will be documented in the recorded-lecture in an electronic form (i.e. Lecturer's web page). Tacit knowledge has been transformed from the lecturers to their students using video-conferencing technology via M-learning.

\section{CONCLUSION}

Knowledge Management helps to identify the gaps and weaknesses in the learning field within BUC. Managing the course-material (lectures, hand-out, and assignments) is the major problem that BUC students are suffering from. This paper suggests a solution that combines four technologies: $M$ learning, E-podium, BUC Website and Videoconferencing. The proposed solution brings many opportunities for both students and educators. The educators can easily upload/update the coursematerial at their convenient to the university website in order to make it easily for the students to access them. The students and educators can use their mobile devices for video-conferencing in the educators' office hours to discuss issues regarding the course-material. The solution guaranteed that any student who is on duty and misses a class will not have his performance affected negatively.

Different types of knowledge management processes have been incorporated in this study such as: socialization through video-conferencing, Externalization where the lecturer's knowledge is recorded into an explicit electronic form, Internalization while the student learns from the recorded lecture and Exchange where coursematerial is transferred and exchanged between the lecturers and their students. This paper provides a solution that can be applied in a wide spectrum of universities all over the world where both lectures and students are extensively using mobiles devices.

\section{REFERENCES}

Abachi, H. R., \& Muhammad, G. (2013). The impact of m-learning technology on students and educators. Computers in Human Behavior.

Al-Buraimi University College. 2010. About Al-Buraimi University College [online]. [Accessed 28th November, 2013]. Available at: http://www.buc.edu.om
Enriquez, A. G. (2010). Enhancing student performance using tablet computers. College Teaching, vol. 58(3), pp. 77-84.

ePODIUM. 2008. PODIUM [online]. [Accessed 28th November, 2013]. Available at: http://www.epodium.info/

Erkollar, A., \& Oberer, B. J. (2012). Anytime. Everywhere. Mobile Learning in Higher Education: Creating a GIS Course. In Computer Applications for Database, Education, and Ubiquitous Computing (pp. 31-37). Springer Berlin Heidelberg.

Geddes, S. J. (2004). Mobile learning in the 21st century: benefit for learners. Knowledge Tree ejournal.

Gikas, J., \& Grant, M. M. (2013). Mobile Computing Devices in Higher Education: Student Perspectives on Learning with Cellphones, Smartphones \& Social Media. The Internet and Higher Education.

King Saud University. 2009. E-PODIUM [online]. [Accessed 28th November, 2013]. Available at: http://ksu.edu.sa/sites/py/en/mpy/knowledgeBuildin g/Pages/E-podium.aspx

Liu, Y., Li, H., \& Carlsson, C. (2010). Factors driving the adoption of m-learning: An empirical study. Computers \& Education, 55(3), 1211-1219.

Perkins, S., \& Saltsman, G. (2010). Mobile learning at Abilene Christian University: Successes, challenges, and results from year one. Journal of the Research Center for Educational Technology, vol. 6(1), pp. 47-54.

Yang, C. Y., Chang, C. T., \& Chien, L. R. (2010, April). A teacher control model of a blended learning environment based on a typical classroom in secondary school. In Computer Engineering and Technology (ICCET), 2010 2nd International Conference on (Vol. 7, pp. V7-720). IEEE. 